\title{
Autism and Visual Impairment: a Review of the Literature
}

\author{
Maggie Butchart ${ }^{1}$ (D) Joseph J. Long ${ }^{2} \cdot$ Michael Brown $^{3} \cdot$ Anne McMillan $^{1} \cdot$ \\ Janice Bain $^{1}$ - Thanos Karatzias ${ }^{3}$
}

Received: 31 March 2016 / Accepted: 11 November 2016/Published online: 5 January 2017

(C) The Author(s) 2017. This article is published with open access at Springerlink.com

\begin{abstract}
Purpose This review presents the evidence on the prevalence of visual impairments in children and adults with Autism Spectrum Disorder (ASD), and the similar behavioural traits associated with both visual impairment and autism.

Method A systematic literature review was conducted using online databases.

Results Seven studies explored the incidence of visual impairments in people with ASD and found a higher incidence of strabismus (squint) (8.3\%) than in a comparable child population (1.5 to $5.3 \%)$. Eleven studies identified behavioural traits common to both autistic and visually impaired populations. The majority were small-scale screening studies using varied methodologies, constituting an emerging field of research.

Conclusion Further large-scale, multicentre studies are required to accurately identify prevalence rates of ophthalmic conditions in people with ASD. There is a small but evolving evidence base that establishes behavioural and linguistic traits common to both visual impairment and autism.
\end{abstract}

Keywords Visual impairment · Sight loss $\cdot$ Autism $\cdot$ ASD

Maggie Butchart

maggie.butchart@rnib.org.uk

\footnotetext{
RNIB Scotland, Kirkcaldy, UK

Scottish Autism, Alloa, UK

Edinburgh Napier University, Edinburgh, UK
}

\section{Introduction}

Autism is a neural developmental disability associated with impairments in communication and social interaction as well as restricted or repetitive interests and behaviours (American Psychiatric Association 2000, 2013). People with autism also frequently experience difficulties in sensory processing (American Psychiatric Association 2013). Communication and interaction difficulties may include delayed language development or a lack of spoken language and impairments in nonverbal communication such as limited eye contact, reduced facial expression and limited expressive gestures. Additionally, individuals with autism often have difficulty processing non-literal and pragmatic elements of speech (Andrews and Wyver 2005; Bowler 2007; Carvill 2001). Repetitive, stereotypical behaviours may include eye pressing, hand flicking, light gazing and rocking (Turner 1999). Similar repetitive behaviours have been evidenced in congenitally blind children, particularly eye poking, rubbing and rocking (Hobson et al. 1999; Kaplan et al. 1999; Scharre and Creedon 1992; Turner 1999). Equally present in both groups are the verbal traits of echolalia and pronominal reversal (Turner 1999). Moreover, children with severe visual impairments suffer from deficits in social and relational development similar to that observed in children with autism (Hobson et al. 1999).

Research indicates visual impairment is frequently undetected amongst children, adults and older people with intellectual disabilities and related conditions that are often referred to collectively as "complex needs" (Emerson and Robertson 2011; van Splunder et al. 2006). This population includes individuals with both autism and intellectual disabilities. Visual impairment is characteristically under-diagnosed in people with complex needs as the signs can be difficult to delineate. Diagnostic overshadowing where one condition may mask another is common in people with intellectual disabilities (Brown et al. 1997; Cass 1998; Turner 1999). 
Undetected visual impairments are likely to impact quality of life, stress levels, receptiveness to new information and therefore the behaviour of individuals with autism. Awareness of sight loss and visual impairment should, therefore, be of concern to those providing care and support for people on the autism spectrum.

The present review focuses on the incidence of ophthalmic conditions in people with ASD. To the best of our knowledge, no previous systematic review has been published to-date on this issue. It is anticipated this review will identify gaps in knowledge which can be used to inform further practice, education and research in this field. It should be noted that the review deals exclusively with ophthalmic conditions; for a review of broader vision and visual processing issues, see Simmons et al. (2009).

\section{Aim and Scope of the Review}

The review aims to draw together existing knowledge of visual impairment and autism to establish the evidence base to answer two questions:

1. What is the prevalence of visual impairments in people with Autism Spectrum Disorder established in the scientific literature?

2. What behavioural traits are established as being associated with both Autism Spectrum Disorder and visual impairment?

\section{Methods}

The literature search was carried out between April and June 2015. A review of online relevant databases was conducted and this included the following: CINHAL, MEDLINE, Psychinfo, Pubmed, OVID, ERIC and EMBASE databases. Primary search terms included combinations the following key words; "autism", "autism spectrum disorder", "blindness", "sight loss" and "visual impairment".

\section{Definitions of Autism and Visual Impairment}

Autism is defined by the American Psychiatric Association's Diagnostic and Statistical Manual of Mental Disorders (DSMIV-TR, DSM-V) (American Psychiatric Association 2000, 2013), the International Classification of Diseases 10 (ICD 10) (World Health Organisation) 2014 or recognised using ASD diagnostic tools such as the Childhood Autism Rating Scale (CARS) developed by Eric Schopler, Robert J. Reichier and Barbara Rochen Renner, and the Autism Behaviour Checklist (ABC) developed by Krug, Arick, and Almond to identify intellectually disabled individuals with high incidences of behaviour associated with autism.

Visual impairment is defined by a range of terms including "blindness", defined by the World Health Organisation (WHO) as vision of $<3 / 60$, that is being unable to see at $3 \mathrm{~m}$ what someone with typical vision can see at $60 \mathrm{~m}$ within $\mathrm{a}<5^{\circ}$ field.

\section{Inclusion and Exclusion Criteria}

The review was restricted to papers published from 20002015. The timeline was selected by researchers to confine the review to recent literature.

The review inclusion and exclusion criteria were as follows:

- Type of paper: Restricted to primary research, published in English in peer-reviewed journals.

- Study Design: For question 1, only studies using quantitative research methods were included. For question 2, both quantitative and qualitative studies were included.

- For question 1, only studies which stated a measure of the prevalence of visual impairment in people with ASD and provided quantitative/statistical estimate of the prevalence were included. For question 2, only studies which directly discussed behavioural indicators of autism as well as typical behaviour associated with visual impairment were included.

\section{Criteria for Inclusion of Autistic Research Samples}

- Population: Studies were included that used the DSM-IVTR criteria (American Psychiatric Association 2000), the International Classification of Diseases 10 (ICD 10) (World Health Organisation 2014) or recognised ASD diagnostic tools (in this case, the CARS and ABC tools) to diagnose or identify individuals as being on the autism spectrum.

\section{Criteria for Inclusion of Visually Impaired Research Samples}

- Studies were included which noted specific ophthalmic disorders or conditions such as strabismus (squint) and refractive errors (long- and short-sightedness) in participants.

- No restrictions were placed on the severity of visual impairment type. No restrictions were placed on the age, ethnicity or socioeconomic status of research subjects. 


\section{Quality Assessment}

The quality of the studies was assessed using a standardised tool, the Quality Assessment Tool for Quantitative Studies (Thomas et al. 2004). The tool consists of nine components: (1) target population selection bias, (2) study design, (3) confounders, (4) blinding, (5) data collection methods and validity, (6) withdrawals and dropouts, (7) intervention integrity, (8) analysis and (9) global ratings. For this review, the fourth, seventh and eight components were not applicable as included studies were cross-sectional or case controlled and therefore did not test an intervention. Included studies were then rated strong, moderate or weak according to the remaining defined criteria outlined in the assessment tool. The component ratings were used to obtain an overall rating. A study was given a global rating of "strong" when there were no weak component ratings, "moderate" when there was one weak rating and "weak" when there were two or more weak component ratings (Thomas et al. 2004).

\section{Synthesis}

A narrative synthesis approach was adopted to integrate the data extracted from the qualifying studies. This approach synthesises findings from multiple studies through an examination of the texts to summarise and explain the findings (Popay et al. 2006). The following key data was extracted and collated from all the included papers: sample size; participant characteristics including gender and age, prevalence rates of coinciding visual impairment and autism; types of ophthalmic condition identified in samples; information on the methods of autism diagnosis; and behavioural traits associated with both autism and visual impairment observed in subjects.

\section{Results}

The combined searches yielded 252 citations (see Fig. 1). A total of 222 studies were excluded that did not meet the inclusion criteria or were duplicates, books or policy documents. At stage II, 52 abstracts were reviewed and a further 28 were excluded. At stage III, 24 papers were retained for secondary evaluation where a further six were excluded as they did not meet the inclusion criteria for at least one of the following reasons:

- Not primary research $(\times 5)$

- Not within the scope of review questions $(\times 1)$

The remaining 18 full text papers were retrieved for detailed review. Seven studies provided data on the prevalence of visual impairments in people with ASD, and 11 provided data on the behavioural traits common to both visual impairment and autism.

The evidence included in this review predominantly involves screening studies with only six studies employing a control group (Dammeyer 2014; Gal et al. 2008; Hartshorne et al. 2005; Hobson and Lee 2010; Hoevenaars-van den Boom et al. 2009; Milne et al. 2009). While the lack of control groups limits the robustness of the evidence, the screening studies provide quality information on the aetiology of a condition. Data from screening studies convey cumulative incidences of features and symptoms that indicate a relationship to a given condition (Mann 2003).

\section{The Prevalence of Visual Impairment in People with ASD}

The evidence relating to the prevalence of sight loss in people with ASD since 2000 is limited to seven studies (Black et al. 2013; Ezegwui et al. 2014; Ikeda et al. 2013; Kabatas et al. 2015; Kielinen et al. 2004; Milne et al. 2009; Mukaddes et al. 2007). Table 1 details the quality of the evidence based on the criteria proposed in the Quality Assessment Tool for Quantitative Studies (Thomas et al. 2004). Six studies were rated as moderate and one as strong according to the above criteria. The moderate ratings were attributed as the papers lacked information on the study design and provided no information on control for confounding variables or dropout rates.

Of the seven studies, one cross-sectional study explored the range of medical disorders in people with autism (Kielinen et al. 2004), five studies screened ASD participants for the presence of ophthalmic conditions (Black et al. 2013; Ezegwui et al. 2014; Kabatas et al. 2015; Ikeda et al. 2013; Milne et al. 2009) while one further study alternated the perspective to examine a visually impaired cohort for ASD (Mukaddes et al. 2007). Table 2 details the participant demographics, study design and findings from the studies included in the review.

Sample size varied across the studies; of the six screening studies, four included large samples which were, respectively, 324 (Kabatas et al. 2015), 257 (Mukaddes et al. 2007), 187 (Kielinen et al. 2004), and 154 (Ikeda et al. 2013). Three were smaller scale studies; Milne et al. (2009) had 51 participants. Black et al. (2013) included 44 subjects and Ezegwui et al. (2014) had 18 subjects.

All seven studies examined child/adolescent subjects with an age range from 1 to 18 years of age. Additionally, Black et al. (2013) included young adults up to the age of 22 but the distribution of ages within the sample was not specified. That all the qualifying studies included young samples means that the incidence of age-related visual impairments remains to be established in the autistic population.

Male predominance has been reported in autism (Fombonne et al. 2011), and in six of the seven studies, male 
Fig. 1 Flow diagram of data retrieved at each stage of the review

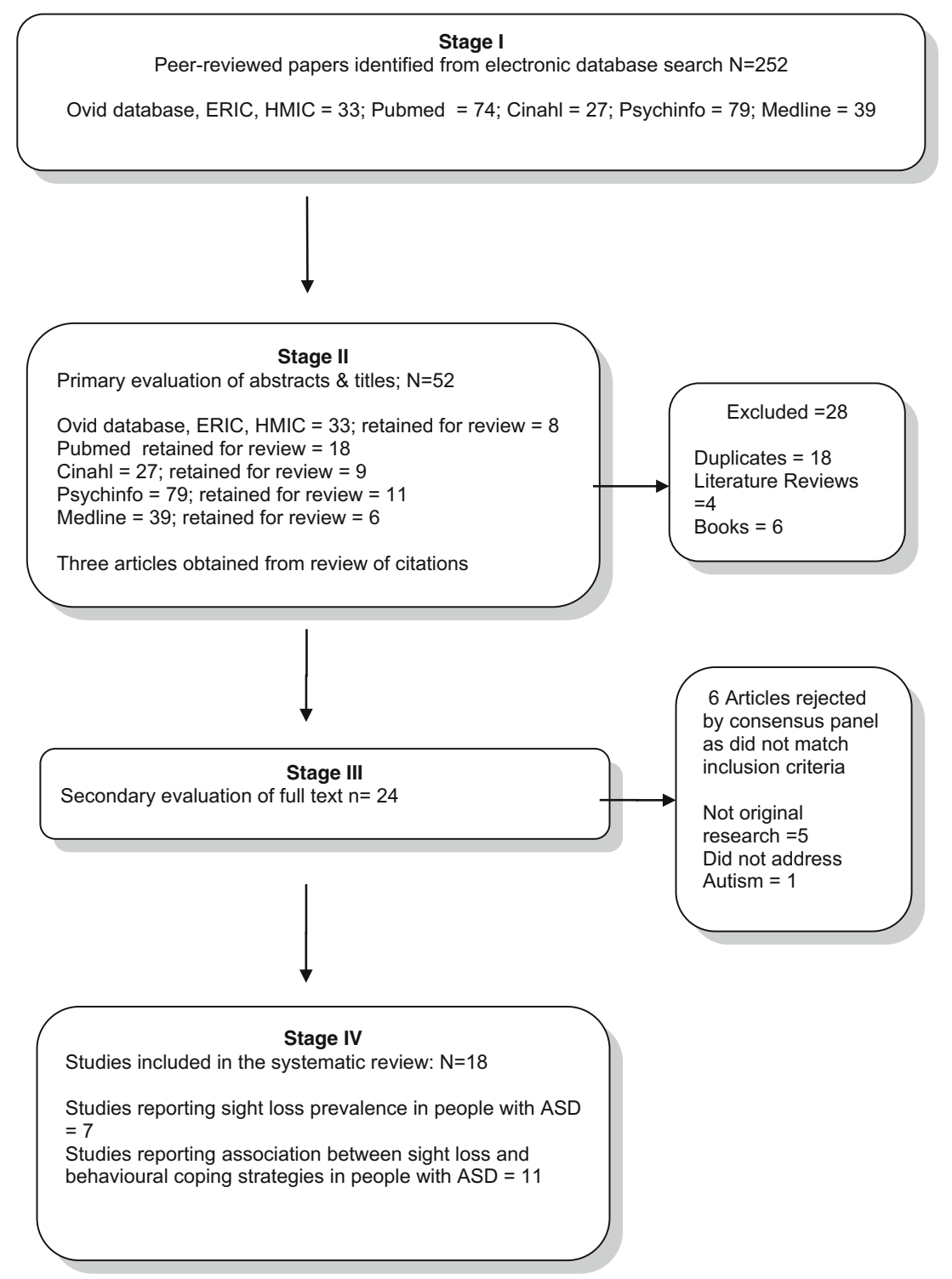

subjects largely dominated. The study by Mukaddes et al. (2007) was 70\% male, Milne et al. (2009) had 86\% male participants in the ASD group, Ikeda et al. (2013) had 79\% males, Black et al. (2013) had 75\% male subjects, Ezegwui et al. (2014), a 72\% male sample, and the sample in Kabatas et al. (2015) was $82 \%$ male. Kielinen et al. (2004) did not specify gender division. The gender balance of the included research samples reflects the male majority in the currently diagnosed autistic population. However, it may be noted that current research relating to possible sex differences in the autism phenotype suggests that females with autism may be under- or mis-diagnosed (Lai et al. 2015; Van WijngaardenCremers et al. 2014) and that the sex ratio of males and females diagnosed with autism may change over time.

As noted above, the screening studies either examined individuals diagnosed with autism and assessed their vision or looked at a visually impaired cohort and assessed them for autism. This is a potentially rigorous study design; however, lack of detail regarding selection criteria and specificity of diagnoses limits the strength of the findings. For example, Milne et al. (2009) screened the vision in children and adolescents with $\operatorname{ASD}(n=51)$ and a typically developing nonmatched control group $(n=44)$, and noted, in the limitations, that not all participants completed all tasks and IQ data were not completed for some participants. Similarly, Ikeda et al. (2013) examined an identified autistic population from a specific clinic and retrospectively examined records for ophthalmic conditions. However, only $38 \%$ of the sample had complete eye examinations.

Table 3 documents the prevalence of refractive errors and strabismus found in each of the studied groups. As the table shows, Kabatas et al. (2015) found that $26.9 \%$ of their participants had refractive errors and $8.6 \%$ strabismus (squint); Black et al. (2013) found $27 \%$ of their sample to have 
Table 1 Quality assessment of seven studies reporting the prevalence of VI in people with autism

\begin{tabular}{|c|c|c|c|c|c|c|c|}
\hline & \multirow[t]{2}{*}{ Study } & \multicolumn{5}{|l|}{ Component rating } & \multirow{2}{*}{$\begin{array}{l}\text { Global } \\
\text { rating }\end{array}$} \\
\hline & & Representativeness & $\begin{array}{l}\text { Study } \\
\text { design }\end{array}$ & Confounders & Validity & Dropout & \\
\hline 1 & $\begin{array}{l}\text { Black et al. } \\
\text { (2013) }\end{array}$ & Moderate & Moderate & Weak & Moderate & Moderate & Moderate \\
\hline 2 & $\begin{array}{l}\text { Ezegwui et al. } \\
\text { (2014) }\end{array}$ & Moderate & Moderate & Weak & Moderate & Moderate & Moderate \\
\hline 3 & $\begin{array}{l}\text { Kabatas et al. } \\
\text { (2015) }\end{array}$ & Moderate & Moderate & Weak & Moderate & Moderate & Moderate \\
\hline 4 & $\begin{array}{l}\text { Kielinen et al. } \\
\text { (2004) }\end{array}$ & Strong & Moderate & Moderate & Strong & Weak & Moderate \\
\hline 5 & $\begin{array}{l}\text { Ikeda et al. } \\
\quad(2013)\end{array}$ & Strong & Moderate & Moderate & Moderate & Weak & Moderate \\
\hline 6 & $\begin{array}{l}\text { Milne et al. } \\
\text { (2009) }\end{array}$ & Moderate & Moderate & Moderate & Strong & Moderate & Strong \\
\hline 7 & $\begin{array}{l}\text { Mukaddes } \\
\text { et al. } \\
\text { (2007) }\end{array}$ & Moderate & Moderate & Moderate & Strong & Weak & Moderate \\
\hline
\end{tabular}

refractive errors and $41 \%$ strabismus. Ikeda et al. (2013) identified $28.7 \%$ with refractive errors and $20.7 \%$ with strabismus. Milne et al. (2009) found $31.4 \%$ with refractive errors and $10.6 \%$ with strabismus. Kielinen et al. (2004) noted that $22.9 \%$ had refractive errors. The study of visually impaired individuals found $11 \%$ of their sample to meet the diagnostic criteria for autism (Mukaddes et al. 2007).

\section{Summary}

Overall, evidence regarding the prevalence of ophthalmic conditions in people with ASD is limited to seven studies with six of the seven achieving a moderate global quality rating. Combining the aggregate evidence from six of the seven studies suggest a refractive error in the childhood ASD populations studied at 22.9-32.7\%, which is comparable with general childhood refractive error rates in 6-7 year olds at $29 \%$, and $32.3 \%$ in 12-13 year olds (O’Donoghue 2010). Estimates of childhood strabismus in the UK is 1.5 to $5.3 \%$ (Pathai et al. 2010), and in the multi-ethnic refractive error study included here, the rate is lower at $0.14 \%$ (Xiao et al. 2015). However, the incidence of strabismus amongst the combined samples included in this review is higher at $8.3 \%$ (Friedman et al. 2009; O’Donoghue et al. 2010; Pathai et al. 2010; Xiao et al. 2015). The seventh study reviewed here examined a congenitally blind population for autism and found $11.6 \%$ with the condition, which is over ten times higher than the estimated prevalence rates for the UK (Baron-Cohen et al. 2009). The moderate global quality rating of these studies would, however, suggest that evidence is not adequate to accurately indicate a definitive prevalence rate of ophthalmic conditions in people with
Autism Spectrum Disorder. The main limitations of the reviewed research include the lack of details in selection criteria and dropout rates, compliance with testing procedures and variation in testing procedures.

\section{What Behavioural Traits Are Established as Being Associated with Both Autism Spectrum Disorder and Visual Impairment?}

The 11 studies which reported common behaviours associated with both visual impairment and ASD (Table 4) were of varying quality. The majority of studies $(n=8)$ achieved a moderate rating as no information was presented on control for confounding variables such as non- matched controls in the analysis. Two studies (Fazzi et al. 2007 and Gal et al. 2008) were considered weak as, additionally, they did not give information on dropout rates.

Of the 11 studies, 6 were screening studies assessing congenitally visually impaired groups for autism (Dammeyer 2014; Fazzi et al. 2007; Hartshorne et al. 2005; Johansson et al. 2006; Smith et al. 2005), 3 were observational screening studies (Gal et al. 2008; Hoevenaars-van den Boom et al. 2009; Williams et al. 2014), 1 was a longitudinal case study which tracked development in congenitally blind children (Hobson et al. 1999), 1 was cross sectional study (JutleyNeilson et al. 2013), and 1 was retrospective case note review (Parr et al. 2010).

Most were based on child and adolescent populations with four having an extended age range to include adults up to the age of 33 (Hartshorne et al. 2005; Hoevenaars-van den Boom et al. 2009; Johansson et al. 2006; Smith et al. 2005), giving a participant age range from 1 month to 33 years of age across 


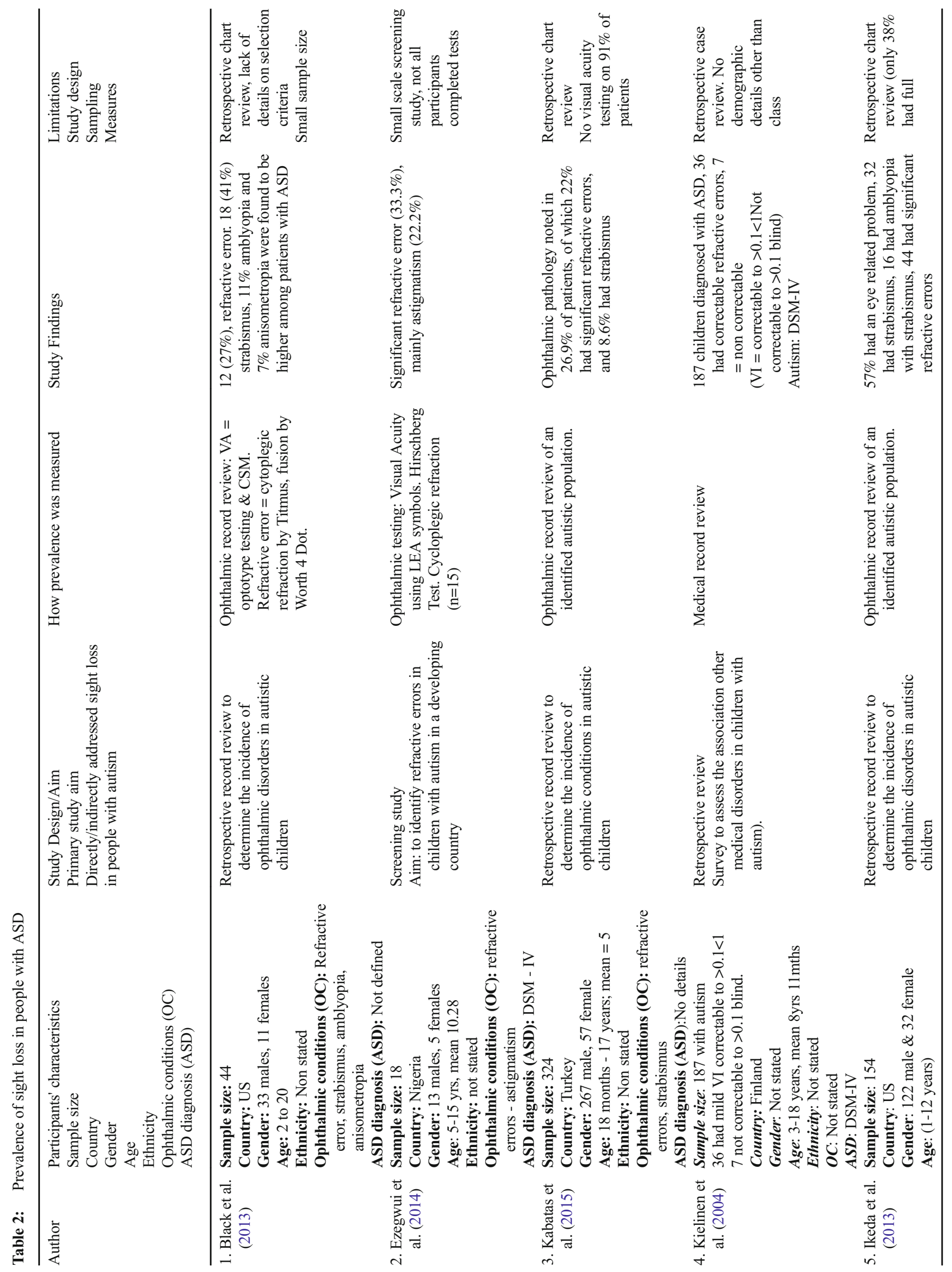




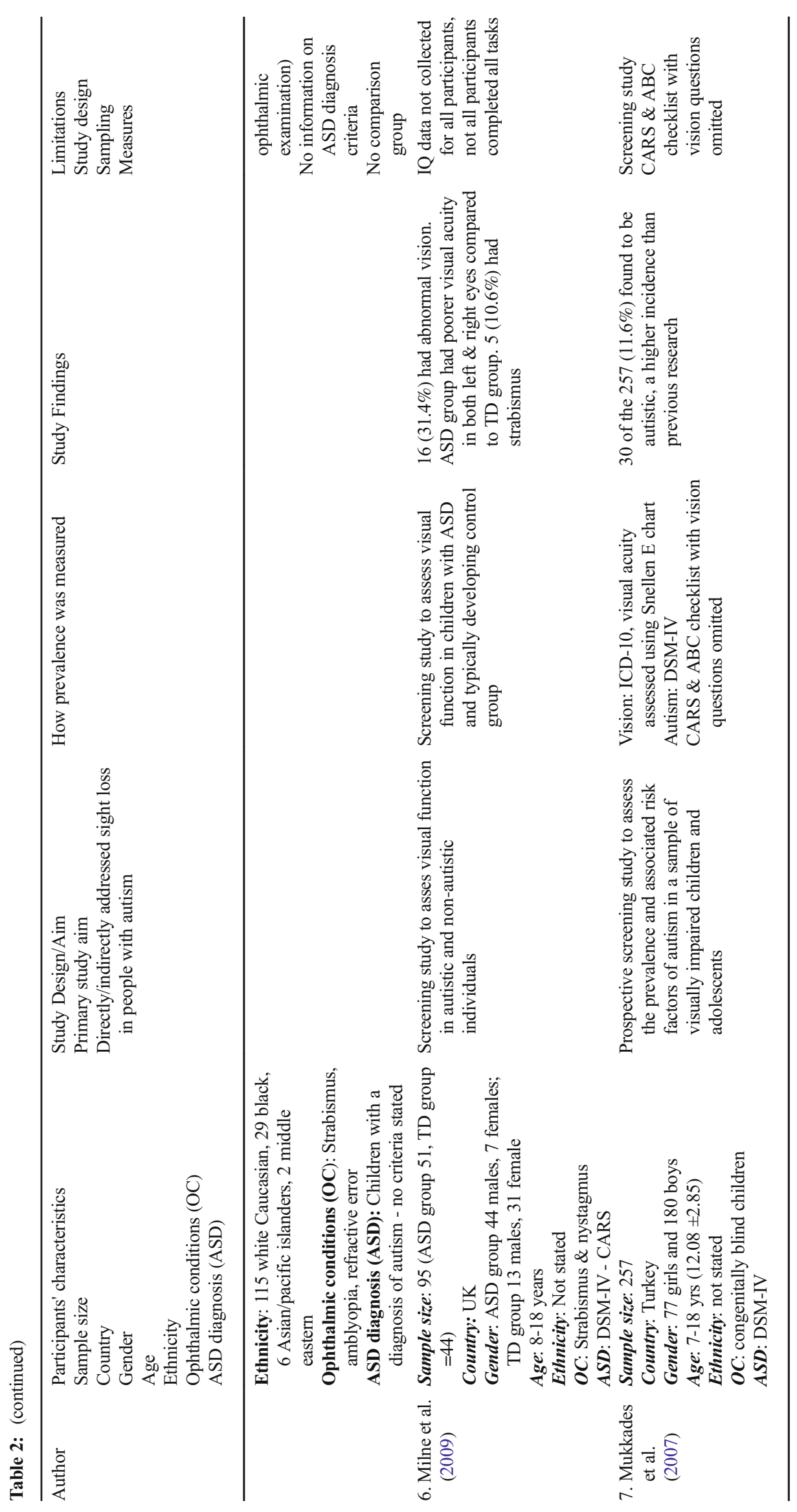


the studies. Overall, there were slightly more males (368) than females (305) in the included studies. Most were small screening studies with only two studies having samples sizes larger than 100 participants (Gal et al. 2008; Hartshorne et al. 2005). Table 5 details the participant demographics, study design and findings from the studies included in the review.

The studies in this review are predominately small screening studies comparing common behaviours in both autistic and visually impaired populations (Dammeyer 2014; Fazzi et al. 2007; Hobson and Lee 2010; Hoevenaars-van den Boom et al. 2009; Johansson et al. 2006; Jutley-Neilson et al. 2013; Parr et al. 2010; Williams et al. 2014). Three of these studies explore autistic behaviours in people with optic nerve hypoplasia (ONH) and Septo-optic dysplasia (SOD) (Jutley-Neilson et al. 2013; Parr et al. 2010; Williams et al. 2014). Two studies examined deaf/blind populations (Dammeyer 2014; Hoevenaars-van den Boom et al. 2009). Four studies examined specific genetic disorders associated with a visual impairment, including three studies on CHARGE, a syndrome effecting different parts of the body that can include coloboma, heart defect, atresia choanae (also known as choanal atresia), retarded growth and development, genital abnormality, and ear abnormality (Johansson et al. 2006; Smith et al. 2005; Williams et al. 2014), and one on Leber's Amaurosis (Fazzi et al. 2007). One seminal study from 1999 (Hobson et al. 1999) reassessed the same group 8 years later for the presence of autism (Hobson and Lee 2010). The final study examined behavioural indicators of autism commonly found in children with congenital visual impairments (Gal et al. 2008).

The majority of studies in this review used the ABC checklist (Dammeyer 2014; Hartshorne et al. 2005) or CARS (Fazzi et al. 2007; Gal et al. 2008; Hobson and Lee 2010) or both (Johansson et al. 2006) to identify autism in visually impaired individuals. It should be noted, however, that these measures have a visual response component which is omitted when testing visually impaired individuals and therefore risks the reliability of the findings. The other studies (Jutley-Neilson et al. 2013; Parr et al. 2010) used the Vineland Adaptive Behaviour Scales (VABS) and Social Communication Questionnaire (SCQ), which were adapted to assess visually impaired individuals (Jutley-Neilson et al. 2013). Adaption again undermines the validity of the measure. Two final studies (Hoevenaars-van den Boom et al. 2009; Williams et al. 2014) used observational measures which were developed to detect autism in the visually impaired. These studies were conducted on small samples of $<15$ participants, which undermines the reliability of the findings. This further highlights the need for a measure that is responsive enough to differentiate between stereotypical behaviour stemming from neurodevelopmental impairment such as autism and those behaviours resulting from visual impairment (Cass 1998; Gal et al. 2008).

The evidence suggests that autistic traits such as limited social interaction and communication, and certain restrictive, repetitive behaviours such as eye poking, pressing, rocking are equally present in children who are congenitally blind (Fazzi et al. 2007; Hobson and Lee 2010; Parr et al. 2010). Noted developmental delay in congenitally blind children can also be observed in traits such as a lack of symbolic play, limited social interaction, and linguistic traits such as echolalia and pronominal reversal, but these may reduce with age (Fazzi et al. 2007; Hobson and Lee 2010; Williams et al. 2014).

Differentiating the causation of common behaviours as stemming from either visual impairment or from a neural developmental condition is not straightforward in deaf/blind and intellectually impaired population (Smith et al. 2005; Hartshoren et al. 2005; Johansson et al. 2006). One study (Hoevenaars-van den Boom et al. 2009) suggested it is possible to differentiate the impairments in social interaction, communication and language caused by sensory impairment from those of autism through close observational assessment (Hoevenaars-van den Boom et al. 2009); however, the small sample size and testing of a developed observational tool limit the generalisability of the findings.
Table 3 Incidence of refractive errors and strabismus (cross eyes)

\begin{tabular}{lllll}
\hline & Listed in year order & Sample size $(n)$ & $N(\%)$ refractive errors & $N(\%)$ strabismus \\
\hline 1 & Black et al. (2013) & 44 & $12(27 \%)$ & $18(41 \%)$ \\
2 & Ezegwui et al. (2014) & 18 & $6(33.3 \%)$ & - \\
3 & Kabatas et al. (2015) & 324 & $73(22.5 \%)$ & $28(8.6 \%)$ \\
4 & Kielinen et al. (2004) & 187 & $43(22.9 \%)$ & - \\
5 & Ikeda et al. (2013) & 154 & $44(28.75 \%)$ & $32(20.7 \%)$ \\
6 & Milne et al. (2009) & 51 & $16(31.4 \%)$ & $5(10.6 \%)$ \\
7 & Mukaddes et al. (2007) & 257 & $30(11.6 \%)^{\mathrm{a}}$ & $36(8.3 \%)$ \\
& Total & 1035 & $237.9(22.98 \%)$ & \\
\hline$-=$ not reported & &
\end{tabular}


Table 4 Quality assessment of the eleven studies reporting ASD behaviours in people with visual impairments

\begin{tabular}{|c|c|c|c|c|c|c|c|}
\hline & \multirow[t]{2}{*}{ Study } & \multicolumn{5}{|l|}{ Component rating } & \multirow[t]{2}{*}{ Global rating } \\
\hline & & Representativeness & Study design & Confounders & Validity & Dropout & \\
\hline 1 & Dammeyer (2014) & Moderate & Moderate & Weak & Strong & Moderate & Moderate \\
\hline 2 & Fazzi et al. (2007) & Strong & Moderate & Weak & Strong & Weak & Weak \\
\hline 3 & Gal et al. (2008) & Moderate & Moderate & Weak & Strong & Weak & Weak \\
\hline 4 & Hartshorne et al. (2005) & Strong & Moderate & Weak & Strong & Weak & Weak \\
\hline 5 & Hobson and Lee (2010) & Moderate & Moderate & Moderate & Strong & Strong & Strong \\
\hline 6 & Hoevenaars et al. (2009) & Strong & Moderate & Weak & Strong & Strong & Moderate \\
\hline 7 & Johansson et al. (2006) & Moderate & Moderate & Weak & Strong & Moderate & Moderate \\
\hline 8 & Jutley-Neilson et al. (2013) & Strong & Moderate & Weak & Strong & Strong & Moderate \\
\hline 9 & Parr et al. (2010) & Strong & Moderate & Moderate & Strong & Weak & Moderate \\
\hline 10 & Smith et al. (2005) & Strong & Moderate & Moderate & Strong & Weak & Moderate \\
\hline 11 & Williams et al. (2014) & Strong & Moderate & Moderate & Strong & Weak & Moderate \\
\hline
\end{tabular}

Two studies (Parr et al. 2010; Jutley-Neilson et al. 2013) found a broad range of impairments common in autism equally present participants with ONH and SOD (30 and 33\%, respectively) particularly social interaction, communication, and repetitive behaviour. Williams et al. (2014) suggest that presentations of autistic behavioural traits may lessen with age in this group; however, findings were based on a small sample of nine.

\section{Summary}

The majority of studies on the similarity between visual impairment and autistic traits were small screening studies, focused on specific visually impaired populations. The evidence suggests that autistic traits such as limited communication and social interaction, in conjunction with repetitive, restrictive behaviours are also evident in children who are congenitally blind; however, the presence of these traits does not necessarily indicate a broad enough range of impairments to warrant an autism diagnosis.

The measures used to define autism have not been systematically tested on a visually impaired population, and the omission of visual components in the standardised autism diagnostic measures undermines their validity and reliability.

\section{Discussion}

\section{Summary of Findings and Limitations}

This review has comprehensively examined ophthalmic conditions in people with Autism Spectrum Disorders. Collating the evidence from six of the seven prevalence studies suggests a refractive error rate in the childhood ASD population studied at $22.9-32.7 \%$, which is comparable with general childhood refractive error rates in 6-7 year olds at $29 \%$, and $32.3 \%$ in 12-13 year olds (O'Donoghue 2010). Estimates of childhood strabismus in the UK is 1.5 to $5.3 \%$ (Pathai et al. 2010), but in the evidence collated in this review, the incidence of strabismus amongst autistic participants is higher at $8.3 \%$ (Friedman et al. 2009; O'Donoghue et al. 2010; Pathai et al. 2010; Xiao et al. 2015). The single study examining a congenitally blind population for autism found $11.6 \%$ meeting the criteria for a diagnosis of ASD, far higher than the estimated prevalence rates of around 1\% for the UK (Baron-Cohen et al. 2009). It should be noted that the review evidence is predominately based on child and adolescent populations. There were no studies examining ophthalmic conditions and adult autistic populations who are more at risk of age-related visual impairments.

The evidence analysed suggests that certain impairments in social interaction and communication, as well as the presentation of stereotyped and repetitive behaviours, are common to both the visually impaired and those with Autism Spectrum Disorder. This research field is dominated by small screening studies on populations with specific congenital visual impairments, which limits the generalisability of the findings. There is a need for a validated measure to assess for ASD which has been tested on the visually impaired populations and is not undermined by the exclusion of a visual response (Hartshorne et al. 2005; Johansson et al. 2006; Gal et al. 2008; Hobson and Lee 2010; Dammeyer 2014). Additionally, there is some evidence that retesting in older children and adolescents is appropriate for the severely visually impaired as difficulties with communication and social interaction may be due to developmental delay and reduce with age (Fazzi et al. 2007; Hobson and Lee 2010; Williams et al. 2014). It should also be noted that available evidence lacks information on participant 


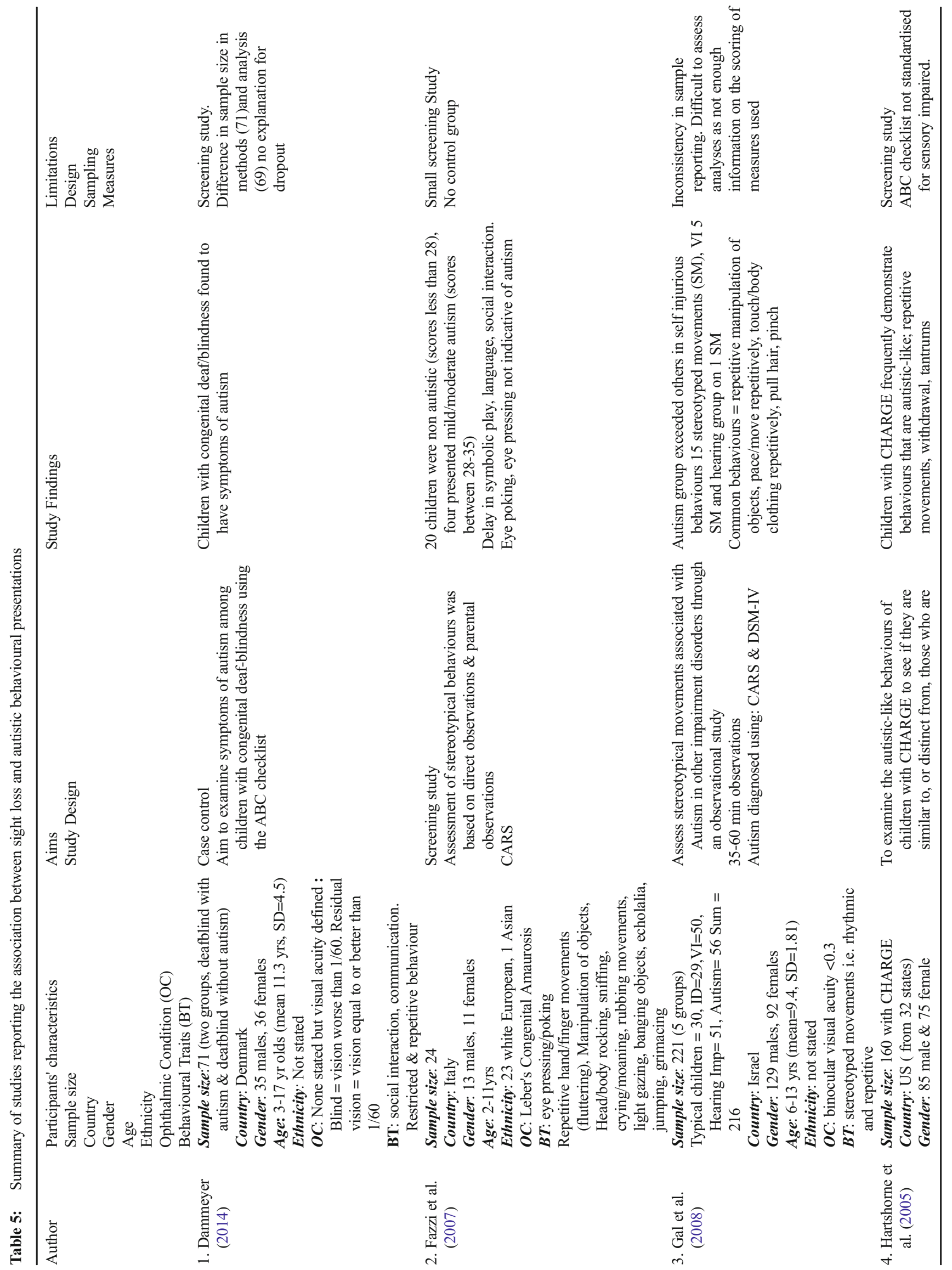




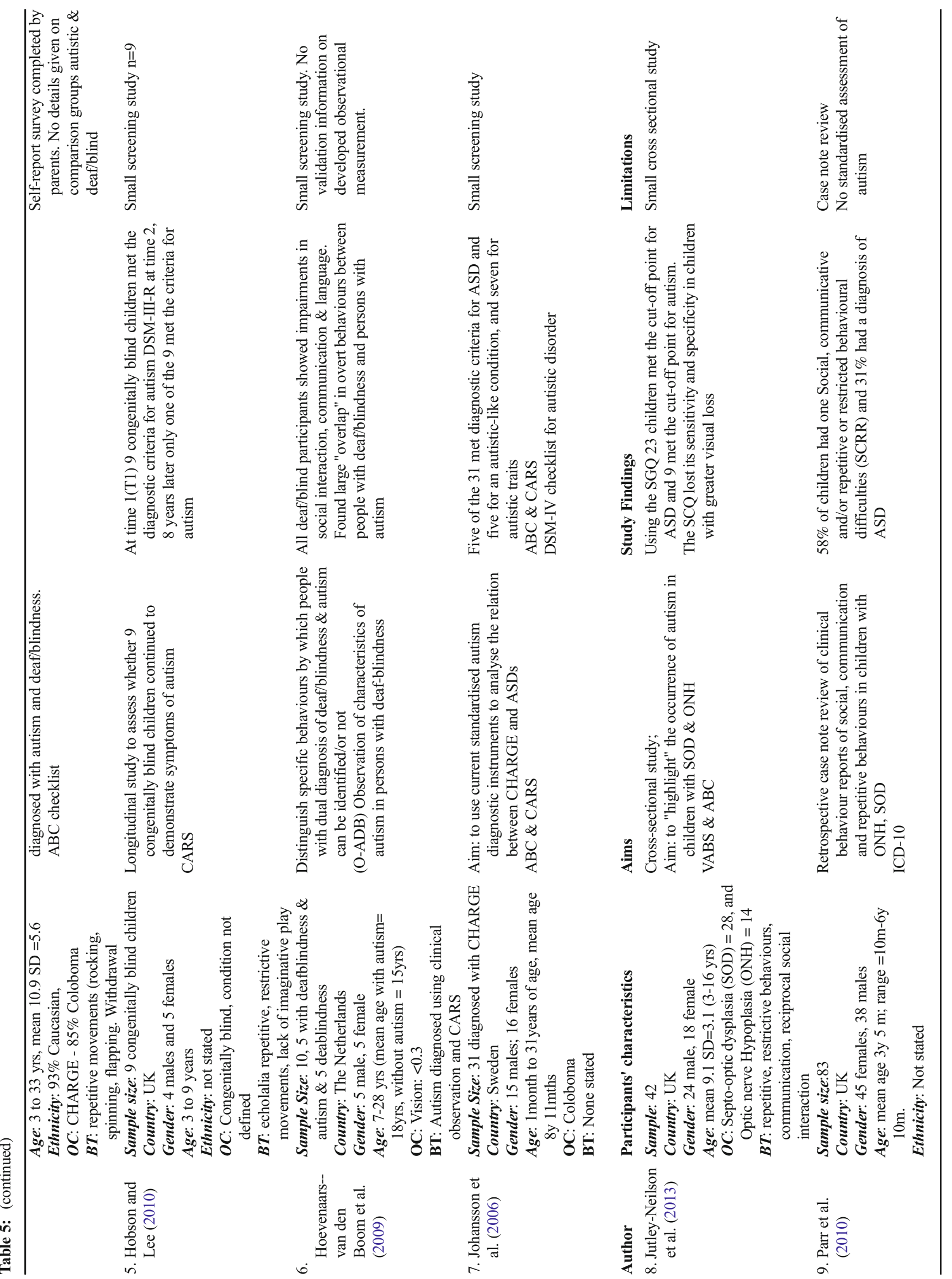


demographics such as ethnicity, social class, IQ level or accounting for the wide age ranges in both of the subject group and control groups (if present) all of which limits the generalisabilty of the findings (Rogers and Ozonoff 2005).

\section{Implications for Autism Support Services}

Given the current reported difficulties in differentiating whether certain developmental and behavioural features are caused by ophthalmic visual impairment or other neurological differences, it is important that individuals diagnosed with autism access regular optometry screening so that ophthalmic conditions can be either diagnosed or ruled out as being associated with an individual's day-today functioning.

Professionals supporting people with autism, particularly individuals with complex needs and limited verbal communication, need to recognise the potential for visual impairments amongst those that they support. An awareness of the similarity in traits means that autism support practitioners must be wary of attributing all impaired communication or stereotypy to an individual's autism diagnosis without considering the possibility of coincidental visual impairment - a phenomenon known as "diagnostic overshadowing" (Hepburn et al. 2014; NICE 2012).

Undiagnosed visual impairment is likely to severely impact quality of life. There is a need therefore for education and training that equip autism support practitioners with the awareness and skills to identify potential visual impairment, to refer individuals to optometry professionals if necessary, and to make necessary adjustments to service environments and support practices for individuals identified as having a visual impairment. Specialist autism services and optometry services are well placed to work collaboratively in order to develop eye care pathways as a means to promote equity of access to optometry assessment and to ensure autism-friendly optometry services (NICE 2012; Venkat et al. 2012). Successful optometry processes are likely to require the presence of carers or autism practitioners with knowledge of an individual that they support and skills to address issues such as increased anxiety when attending appointments for optometry assessment (Chiri and Warfield 2011). Optometrists may also need to undertake reasonable adjustments to diagnostic processes that enable access for assessment for people with autism (Coulter 2009; Turner and Robinson 2011).

\section{Directions for Future Research}

In systematically identifying and reviewing the literature relating to visual impairments in people with autism, it is evident that further research is required to investigate the prevalence of cooccurring autism and visual impairment. Researchers should also seek to ascertain whether it is possible to develop screening and diagnostic processes that can differentiate where common behavioural traits stem from visual impairment and where such traits 
are rooted in other, neurodevelopmental differences that underlie Autism Spectrum Disorder. This may be achieved through standardised autism diagnostic measures that incorporate components for the assessment of sensory-impaired individuals. Further research is needed that provides detailed demographics of the subject groups under observation and the exact diagnoses of the visual impairment. It is hoped that the findings from this systematic review will raise awareness of the extent to which visual impairment may be experienced by people with autism, and this in turn will inform professional practice ensuring that individuals with autism and visual impairment receive appropriate diagnosis and support.

\section{Compliance with Ethical Standards}

Funding This review was funded by the Scottish Government through the Scottish Strategy for Autism

Conflict of Interest The authors declare that they have no conflict of interest

Open Access This article is distributed under the terms of the Creative Commons Attribution 4.0 International License (http:// creativecommons.org/licenses/by/4.0/), which permits unrestricted use, distribution, and reproduction in any medium, provided you give appropriate credit to the original author(s) and the source, provide a link to the Creative Commons license, and indicate if changes were made.

\section{References}

Andrews, R., \& Wyver, S. (2005). Autistic tendencies: are there different pathways for blindness and autism spectrum disorder? British Journal of Visual Impairment, 23(2), 52-57.

American Psychiatric Association (2000). Diagnostic and statistical manual of mental disorders (4th ed, text rev.), Washington DC

American Psychiatric Association (2013). Diagnostic and statistical manual of mental disorders (4th ed, text rev.), Washington DC

Baron-Cohen, S., Scott, F. J., Allison, C., Williams, J., Bolton, P., Matthews, F. E., et al. (2009). Prevalence of autism-spectrum conditions: UK school-based population study. The British Journal of Psychiatry, 194(6), 500-509.

Black, K., McCarus, C., Collins, M. L. Z., \& Jensen, A. (2013). Ocular manifestations of autism in ophthalmology. Strabismus, 21(2), 98-102.

Bowler, D. (2007). Autism spectrum disorders: psychological theory and research. West Sussex: John Wiley \& Sons, Ltd.

Brown, R., Hobson, R. P., \& Lee, A. (1997). Are there "autistic-like" features in congenitally blind children? Journal of Child Psychology and Psychiatry, 38(6), 693-703.

Carvill, S. (2001). Sensory impairments, intellectual disability and psychiatry. Journal of Intellectual Disability Research, 45(6), 467-483.

Cass, H. (1998). Visual impairment and autism. Autism, 2(2), 117-138.

Chiri, G., \& Warfield, M. E. (2011). Unmet need and problems accessing core health care services for children with Autism Spectrum Disorder. Maternal and Child Health Journal, 16(5), 1081-1091.
Coulter, R. A. (2009). Understanding the visual symptoms of individuals with autism spectrum disorder (ASD). Optometry and Vision Development, 40(3), 164-175.

Dammeyer, J. (2014). Symptoms of autism among children with congenital deafblindness. Journal of Autism and Developmental Disorder, $44,1095-1102$.

Emerson, E., \& Robertson, J. (2011). The estimated prevalence of visual impairment among people with learning disabilities in the UK.

Ezegwui, I. R., Lawrence, A. E., Aghaji, A. E., Okoye, O. I., Okoye, O., Onwsigwe, E. N., et al. (2014). Refractive errors in children with autism in a developing country. Nigerian Journal of Clinical Practice, 17(4), 467-470.

Fazzi, E., Rossi, M., Signorini, S., Rossi, G., Bianchi, P. E., \& Lanzi, G. (2007). Leber's congenital amaurosis: is there an autistic component? Developmental Medicine and Child Neurology, 49, 503-507.

Fombonne, E., Quirke, S., \& Hagen, A. (Eds.). (2011). Epidemiology of pervasive development disorders (Vol. 90-111). New York: Oxford University Press.

Friedman, D. S., Repka, M. X., Katz, J., Giordano, L., Ibironke, J., Hawse, P., et al. (2009). Prevalence of amblyopia and strabismus in white and African American children aged 6 through 71 months: the Baltimore Pediatric Eye Disease Study. Ophthamology, 116(11), 2128-2134.

Gal, E., Dyck, M. J., \& Passmore, A. (2008). The relationship between stereotyped movements and self-injurious behavior in children with developmental or sensory disabilities. Research in Developmental Disabilities, 30, 342-352.

Hartshorne, T. S., Grialou, T. L., \& Parker, K. R. (2005). Autistic-like behavior in CHARGE syndrome. American Journal of Medical Genetics, 133A, 257-261.

Hepburn, S., Stern, J. A., Blakeley-Smith, A., Lila, K., Kimel, L. K., \& Reaven, J. (2014). Complex psychiatric comorbidity of a treatmentseeking youth in Autism Spectrum Disorder and anxiety symptoms. Journal of Mental Health Research in Intellectual Disabilities, 7(4), 359-378.

Hobson, R. P., \& Lee, A. (2010). Reversible autism among congenitally blind children? A controlled follow-up study. Journal of Child Psychology and Psychiatry, 51, 1235-1241.

Hobson, R. P., Lee, A., \& Brown, R. (1999). Autism and congenital blindness. Journal of Autism and Developmental Disorder, 29(1), 45-56.

Hoevenaars-van den Boom, M. A., Antonissen, A. C., Knoors, H., \& Vervloed, M. P. (2009). Differentiating characteristics of deafblindness and autism in people with congenital deafblindness and profound intellectual disability. Journal of Intellectual Disability Research, 53, 548-558.

Ikeda, J., Davitt, B. V., Ultmann, M., Maxim, R., \& Cruz, O. A. (2013). Brief report: incidence of ophthalmologic disorders in children with autism. Journal of Autism and Developmental Disorder, 43, 1447-1451.

Johansson, M., Rastam, M., Billstedt, E., Danielsson, S., Stromland, K., Miller, M., et al. (2006). Autism spectrum disorders and underlying brain pathology in CHARGE association. Developmental Medicine and Child Neurology, 48, 40-50.

Jutley-Neilson, J., Harris, G., \& Kirk, J. (2013). The identification and measurement of autistic features in children with septo-optic dysplasia, optic nerve hypoplasia and isolated hypopituitarism. Research in Developmental Disabilities, 34, 4310-4318.

Kabatas, E. U., Ozer, P. A., Ertugrul, G. T., Kurtul, B. E., Bodur, S., \& Alan, B. E. (2015). Initial ophthalmic findings in Turkish children with autism spectrum disorder. Journal of Autism and Developmental Disorder, 45(8), 2578-2581.

Kaplan, M., Rimland, B., \& Edelson, S. M. (1999). Strabismus in autism spectrum disorder. Focus on Autism and Other Developmental Disabilities, 14, 101-105.

Kielinen, M., Rantala, H., Timonen, E., Linna, S., \& Moilanen, I. (2004). Associated medical disorders and disabilities in children with autistic disorder. Autism, 8(49-60). 
Lai, M. C., Lombardo, M. V., \& Auyeung, B. (2015). Sex/gender differences and autism: setting the scene for future research. Journal of the American Academy of Child and Adolescent Psychiatry, 54, 11-24.

Mann, C. J. (2003). Observational research methods. Research design II: cohort, cross sectional and case-control studies. BMJ, 20, 54-60.

Milne, E., Griffiths, H. J., Buckley, D., \& Scope, A. (2009). Vision in children and adolescents with autistic spectrum disorder: evidence of reduced convergence. Journal of Autism and Developmental Disorder, 39, 965-975.

Mukaddes, N. M., Kilincaslan, A., Kucukyazici, G., Sevketoglu, T., \& Tuncer, S. (2007). Autism in visually impaired individuals. Psychiatry and Clinical Neurosciences, 61, 39-44.

NICE (2012). Autism in adults: diagnosis and management. https://www. nice.org.uk/guidance/cg142/chapter/1-guidance.

O’Donoghue, L., McClelland, J. F., Logan, N. S., Rudnicka, A. R., Owen, C. G., \& Saunders, K. J. (2010). Refractive error and visual impairment in school children in Northern Ireland. Journal of Ophthalmology, 94, 115-1159.

Parr, J. R., Dale, N., Shaffer, L. M., \& Salt, A. (2010). Social communication difficulties and autism spectrum disorder in young children with optic nerve hypoplasia and/or septo-optic dysplasia. Developmental Medicine and Child Neurology, 52, 917-921.

Pathai, S., Cumberland, P. M., \& Rahi, J. S. (2010). Prevalence of, and early-life influences on childhood strabismus: findings from the Millennium Cohort Study. Archives of Pediatrics \& Adolescent Medicine, 164(3), 250-257.

Popay, J., Roberts, H., A., S., Petticrew, M., Arai, L., Rodgers, M., et al. (2006). Guidance on the conduct of narrative synthesis in systematic reviews: a product from the ESRC Methods Programme. In www. researchgate.net/publication/233866356 (Eds.).

Rogers, S. J., \& Ozonoff, S. (2005). Annotation: what do we know about sensory dysfunction in autism? A critical review of the empirical evidence. Journal of Child Psychology and Psychiatry, 46(12), $1255-1268$

Scharre, J. E., \& Creedon, M. P. (1992). Assessment of visual function in autistic children. Optometry and Vision Science, 69(6), 433-439.

Simmons, D. R., Robertson, A. E., McKay, L. S., Toal, E., McAleer, P., \& Pollick, F. E. (2009). Vision in autism spectrum disorders. Vision Research, 49, 2705-2739.
Smith, I. M., Nichols, S. L., Issekutz, K., \& Blake, K. (2005). Behavioral profiles and symptoms of autism in CHARGE syndrome. American Journal of Medical Genetics, 133A, 248-256.

Thomas, B. H., Ciliska, D., Dobbins, M., \& Micucci, S. (2004). A process for systematically reviewing the literature: providing the research evidence for public health nursing interventions. Worldviews on Evidence-Based Nursing, 1(3), 176-184.

Turner, M. (1999). Annotation: repetitive behaviour in autism: a review of psychological research. Journal of Child Psychology and Psychiatry, 40(6), 839-849.

Turner, S., \& Robinson, C. (2011). Reasonable adjustments for people with learning disabilities-implications and actions for commissioners and providers of healthcare. Bristol: Learning Disability Observatory.

van Splunder, J., Stilma, J. S., Bernsen, R. M. D., \& Evenhuis, H. M. (2006). Prevalence of visual impairments in adults with intellectual disabilities in the Netherlands: cross-sectional study. Eye, 20, 1004-1010.

Van Wijngaarden-Cremers, P. J., Van Eeten, E., Groen, W. B., Van Deurzen, P. A., Oosterling, I. J., \& Van der Gaag, R. J. (2014). Gender and age differences in the core triad of impairments in autism spectrum disorders: a systematic review and meta-analysis. Journal of Autism and Developmental Disorders, 44(3), 627-635.

Venkat, A., Jauch, E., Russell, W. S., Crist, C. R., \& Farrell, R. (2012). Care of the patient with an autism spectrum disorder by the general physician. Postgraduate Medicine, 88(1042), 472-481.

Williams, M. E., Fink, C., Zamora, I., \& Borchert, M. (2014). Autism assessment in children with optic nerve hypoplasia and other vision impairments. Developmental Medicine and Child Neurology, 56, 66-72.

World Health Organisation (WHO). (2014). Visual Impairment and blindness (Fact Sheet No.282), http://www.who.int/mediacentre/fact sheets/fs282/en/.

Xiao, O., Morgan, I. G., Ellweing, L. B., \& Mingguang, H. (2015). Prevalence of amblyopia in school-aged children and variations by age, gender, and ethnicity in a multi-country refractive error study. Ophthamology, 122(9), 1924-1931. 